\title{
Computer Aided Comparative Analysis of the Effects of Superheating and Subcooling on the Performance of R134a and R717 in Simple Vapour Compression Systems
}

\author{
E. G. Saturday \\ Dept. of Mechanical Engrg., \\ University of Port Harcourt
}

\author{
C. E. Chidebe \\ Ref.\&Aircon. Dept., Skill G \\ Research Inst. Abuja, Nigeria
}

\author{
U. Nwaiwu \\ Ref.\&Aircon. Dept., Skill G \\ Research Inst. Abuja, Nigeria
}

\begin{abstract}
This work presents the computer aided comparative analysis of the effects of subcooling and superheating on the performance of R134a and R717 in simple vapour compression refrigeration systems. The analysis was done by carrying out a comprehensive study of the simple vapour compression refrigeration systems, determining the subcooling and superheating parameters by calculation and developing a computer program for the analysis and results generation. The results obtained show that superheating is not an ideal way of improving performance with R717 as the COP reduces with increasing superheat temperature, rather subcooling the refrigerant gives an improvement in the COP of the system. On the other hand, both subcooling and superheating refrigerant R134a improve the performance of the system as the COP increases with the subcooling and superheating temperatures. These were presented graphically using the MATLAB programming language. The program developed for this study can also be used for examination purposes to reduce the work load for the lecturer and to also ensure accuracy of results.
\end{abstract}

\section{Keywords}

Refrigeration, Subcooling, Superheating, Vapour Compression system

\section{INTRODUCTION}

Refrigeration, cooling, and heating processes are important in a variety of everyday situations, including the air conditioning and heating of buildings, hospitals, operation theatres, hotels, restaurants, automobiles and transportation. Refrigeration also finds large-scale industrial applications, especially in the manufacture of ice, dehydration of gases, domestic and commercial refrigerators, large scale warehouses for storage and preservation of foods and beverages and a host of other commercial and industrial services [1]. Vapour compression refrigeration systems are the most commonly used of all refrigeration systems, belonging to the class of vapour cycles, as the name implies. In vapour compression refrigeration systems(VCRS), the working fluid(refrigerant), undergoes phase change during the refrigeration process as the refrigerant evaporates at low temperature. In application,VCRS are also called mechanical refrigeration systems owing to the fact that the input to the system is in the form of mechanical energy needed for the running of the compressor. Vapour compression refrigeration cycles have two advantages. First, a large amount of thermal energy is required to change a liquid to a vapor, and therefore a lot of heat can be removed from the air-conditioned space. Second, the isothermal nature of the vaporization allows extraction of heat without raising the temperature of the working fluid to the temperature of whatever is being cooled. This means that the heat transfer rate remains high, because the closer the working fluid temperature approaches that of the surroundings, the lower the rate of heat transfer.

In the past, attention was given to the performance of normal refrigeration systems without taking into consideration the subcooling and superheated areas. Particularly, subcooling involves reducing the temperature of the liquid refrigerant to within a few degrees of the temperature of the water entering the condenser usually by introducing a subcooler between the condenser and the expansion valve. On the other hand, superheating involves the raising of the temperature of the liquid refrigerant within a few degrees of temperature to ensure a complete vapourisation of the liquid refrigerant in the evaporator before it enters the compressor [2]. Consequently, this study considers the effects at these regions where subcooling and superheating take place, that is, outside the saturation region of the system. In practice, a wide variety of refrigerants can be used in these systems depending on the application and capacity of the system, thus this study was done using refrigerants, $\mathrm{R}-717\left(\mathrm{NH}_{3}\right)$ and $\mathrm{R}-134 \mathrm{a}\left(\mathrm{CF}_{3} \mathrm{CH}_{2} \mathrm{~F}\right)$.

Several works bordering on performance of VCRS abound. Linton et.al [3] carried out a study to compare the performance of refrigerants R-134a and R-12 in a residential exhaust heat pump. Linton et.al [4] also studied the effect of condenser liquid subcooling on system performance for refrigerant R-12, R-134a and R-152a. The works thus do not put into consideration the effects of superheating on the system performance. Pannock et.al [5] evaluated the characteristics of R-134a and R-152a as working fluid in a domestic refrigerator/freezer. The study did not consider in detail, the effects of subcooling and superheating on the performance of the system. Yi Yie Yan et.al [6] studied the characteristics of refrigerant R-134a considering the condensation and evaporative heat transfer and the pressure in plate heat exchanger in small pipes. This study is limited to refrigerant R-134a only. Adegoke et.al [7] did an experimental investigation of the performance of a proposed design model for vapour compression refrigeration systems. Adegoke et.al [8] also did a comparative exergetic analysis of vapour compression refrigeration systems in the subcooled and superheated regions using a two-vapour compression refrigeration system, concentrating on the energy consumption and how to reduce the cost of performance of the system. Sencan et.al [9] presented a thermodynamic analysis of subcooling and superheating effects of alternating refrigerants for vapour compression refrigeration systems. Several other researchers [10]-[12] have considered the performance of vaour compression systems, but each focusing on different aspects. Vaibhav et.al [1] carried out a 
comparative performance study of vapour compression refigeration systems with R-22, R-134a,R-407c, R-410a and $\mathrm{M}-20$, considering the subcooling and superheating effects on the performance of the system. A computer based analysis of the work was not presented. In this work, the effects of subcooling and superheating on the perfornance of refrigerants R-134a and R-717 are presented using a computer-based analysis. This will aid the performance analysis of simple vapour compression refrigeration systems as well as comparing the effects of subcooling and superheating for other set of refrigerants that may be considered. Also, ways of improving the performance of simple vapour compression systems are profered.

\section{THEORETICAL ANALYSIS}

The basic components of a simple vapour compression refrigeration system (SVCRS) are the compressor, the condenser, the expansion or throttling device and the evaporator. There are a lot of other devices such as regulators and controls which aid the smooth flow of the refrigerant through the various components. Figure 1 shows the basic component of the simple vapour compression refrigeration system.

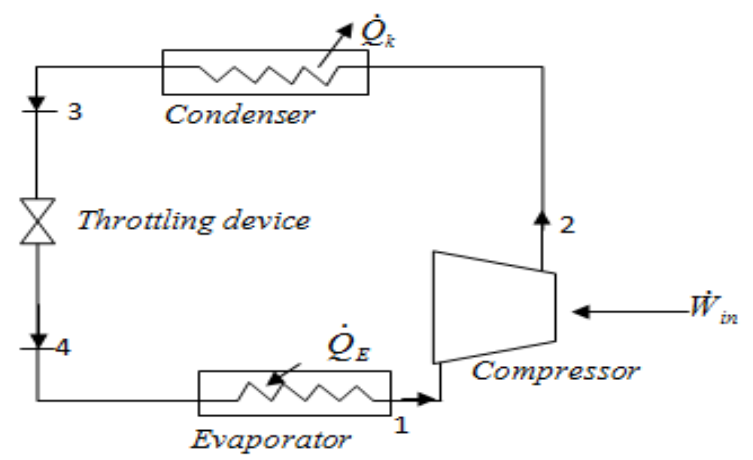

Fig 1: The basic components of a simple vapour compression refrigeration system

For the purpose of performance analysis, the SVCRS is best put in P-h and T-s diagrams as in Figures 2 and 3 respectively. In Figure 2(a), $P_{E}=$ Evaporator Pressure; $P_{k}=$ Condenser pressure; $\mathrm{h}_{\mathrm{i}}=$ Enthalpy at various states, $q_{e}$ is the refrigeration effect in $(\mathrm{kJ} / \mathrm{kg})$ while $w_{c}$ is the specific compressor work input in $(\mathrm{kJ} / \mathrm{kg})$. The refrigerant enters the compressor at state 1 as dry saturated vapour, while it leaves the condenser as saturated liquid.

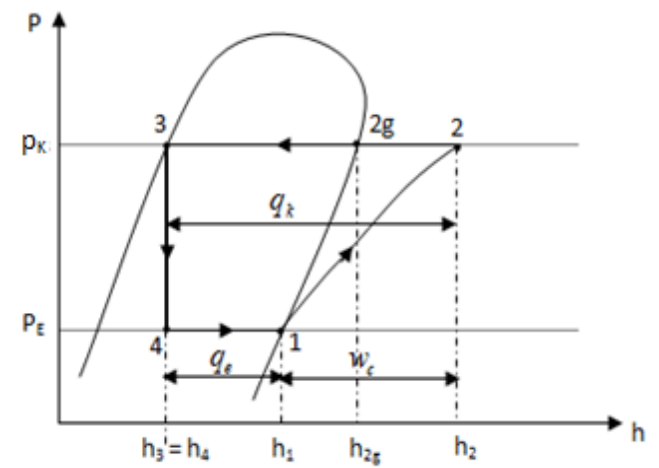

Fig 2: (a) P-h diagram of simple vapour compression system
Figure 2(b) shows the case where the refrigerant enters the compressor as a superheated vapour and leaves the condenser as a subcooled liquid. States 1, 2, 2g, 3 and 4 are the same as stated above. States 1', 2', 3' and 4' are obtained with superheat and subcooling. Here, the refrigerant enters the compressor at state 1' and exits at state 2'. It leaves the condenser at state 3' and enters the evaporator at state 4'. Both superheating and subcooling increase the refrigerating effect, but their combined effect increases the refrigerating effect further (see Figure 2(b)). The state points are also shown in the T-s diagram in Figure 3.

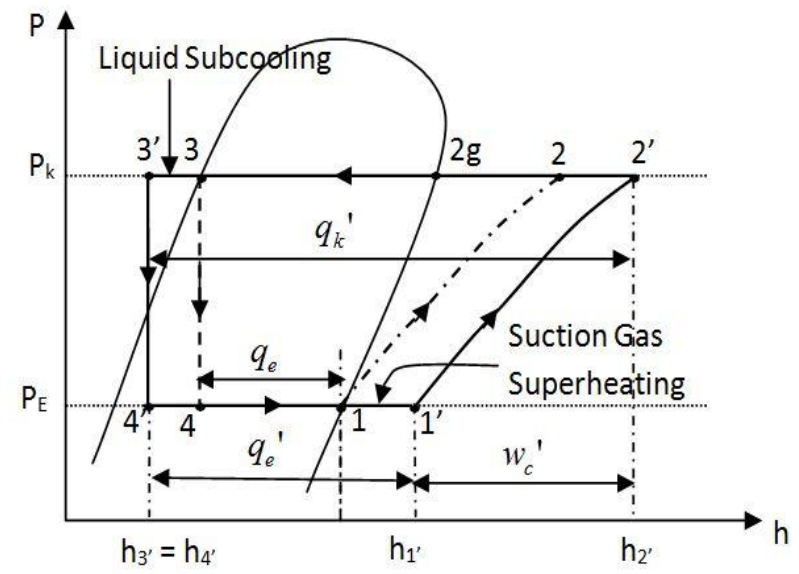

Fig 2: (b) Simple vapour compression system with superheat and subcooling

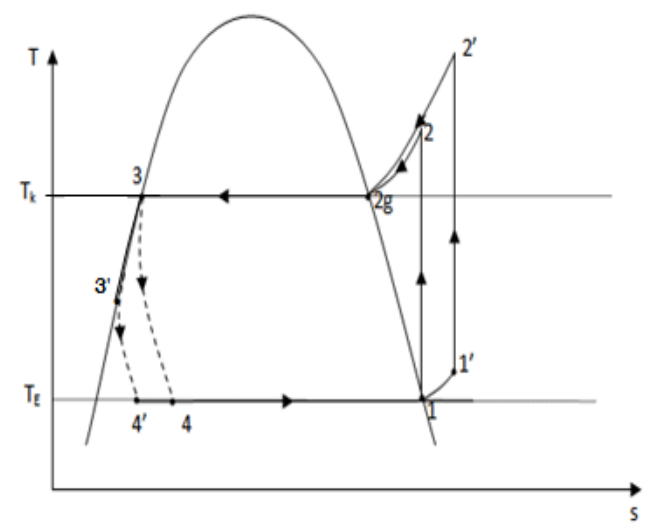

Fig 3: T-s diagram simple vapour compression system with superheat and subcooling

From Figure 3, $t_{1}{ }^{\prime}>t_{1} \cdot t_{3}>t_{3} \cdot t_{1}=t_{4}=t_{E}$ and $t_{2 g}=t_{3}=t_{K}$. State points $2 \mathrm{~g}$ and 2 are at the same pressure level. But $t_{2}>t_{2 g}$, where $t_{2 g}$ is the saturation temperature at the condenser pressure. Thus, $\mathrm{t}_{2}$ is in the superheated region.

\subsection{Cycle Analysis of a SVCRS}

A simple analysis of simple vapour compression refrigeration system can be carried out by assuming steady flow, negligible kinetic and potential energy changes across each component, and no heat transfer in connecting pipe lines. The steady flow energy equation is applied to each of the four components. The performance of the plant is defined by its coefficient of performance (C.O.P.) given by Equation (1),

$$
(\text { C.O.P. })_{R}=\frac{\text { Re frigerating capacity }}{\text { Compressor power input }}
$$




\section{$=\frac{\text { Re frigerating effect }}{\text { specific compressor work input }}$$$
=\frac{q_{e}}{w_{c}}=\frac{h_{1}-h_{4}}{h_{2}-h_{1}}
$$

$q_{e}$ is the refrigerating effect and $w_{c}$ is the specific compressor work, and $(\text { C.O.P. })_{R}$ is the COP for the refrigerating plant. But,

$h_{1}=h_{g @ P_{E}}$ and $h_{4}=h_{3}=h_{f @ P_{K}}$. Thus,

$(\text { C.O.P. })_{R}=\frac{h_{1}-h_{4}}{h_{2}-h_{1}}=\frac{h_{g @ P_{E}}-h_{f @ P_{K}}}{h_{2}-h_{g @ P_{E}}}$

The compressor work $\dot{W}_{c}$ input and the refrigerating capacity $\dot{Q}_{E}$ are given by Equations (3) and (4) respectively,

$$
\begin{gathered}
\dot{W}_{c}=\dot{m} h_{2}-m h_{1}=\dot{m}\left(h_{2}-h_{1}\right) \\
\dot{Q}_{E}=\dot{m}\left(h_{1}-h_{4}\right)
\end{gathered}
$$

where $\dot{m}$ is the mass flow rate of the refrigerant. In some quarters, $\dot{Q}_{E}$ is also referred to as refrigerating effect. The specific energy terms could be easily derived from the P-h diagram.

\subsubsection{Actual Compressor Power Input}

The actual power input to a compressor is greater than that presented in Equation (3). This is because aside the fact that the compression process is not isentropic, there are other losses. Taking $\eta_{m}$ as the mechanical efficiency of the compressor, the actual compressor work input is,

$$
\dot{W}_{a c}=\frac{\dot{W}_{c}}{\eta_{m}}=\frac{\dot{m}\left(h_{2}-h_{1}\right)}{\eta_{m}}
$$

If the motor efficiency $\eta_{m t}$ is considered also, the actual power input to the compressor will be,

$$
\dot{W}_{a c}=\frac{\dot{W}_{c}}{\eta_{m} \eta_{m t}}=\frac{\dot{m}\left(h_{2}-h_{1}\right)}{\eta_{m} \eta_{m t}}
$$

\subsubsection{Determination of State Properties}

Using a table of properties of any refrigerant, properties along the saturation curve could be read. With reference to Figure 2(a), the enthalpies at state points $1,2 \mathrm{~g}$ and 3 are read at the given pressure levels. But the enthalpy at state point 2 which is at the same entropy level with state point $1\left(s_{2}=s_{1}\right)$ could not be obtained from tables because it is in the superheated region. We have to determine $h_{2}$ in order to evaluate the C.O.P. presented above.

\subsubsection{Determination of $h_{2}$, the Enthalpy at the} Compressor Exit

The enthalpy at the compressor exit $\mathrm{h}_{2}$ could be determined by various means. It can be determined in three different ways. These are the use of P-h chart, by calculation exploiting the second law of thermodynamics and by interpolation. For the scope of this study, we restrict the discussion to determination by calculation. The enthalpy of the refrigerant at any state point could be expressed by Equation (7),

$$
h=c_{p} T
$$

$c_{p}$ is the specific heat of the refrigerant in $\mathrm{kJ} / \mathrm{kgK} . c_{p}$ is usually expressed as,

$$
c_{p}=a+b T+c T^{2}+\ldots
$$

But in this case, we assume $c_{p}$ to be constant at the various pressure levels. Thus, it is left simply as $c_{p v}$; the specific heat in the vapour state. Considering state points $2 \mathrm{~g}$ and 2 , (see Figure 2), the difference in enthalpy is expressed by Equation (9)

$$
d h=h_{2}-h_{2 g}=c_{p v}\left(T_{2}-T_{2 g}\right)=c_{p v} d T
$$

But,

$$
\begin{aligned}
& h=u+p v \\
& d h=d u+p d v+v d p=d u+p d v \\
& d p=0 \quad \text { - constant pressure. } \\
& d h=d q \quad ; d u+p d v=d q
\end{aligned}
$$

From the Second Law,

$$
\begin{aligned}
& d q=T d s \\
& \therefore d h=T d s \\
& c_{p v} d T=T d s \Rightarrow d s=\frac{c_{p v}}{T} d T \\
& s_{2}-s_{2 g}=\int_{2 g}^{2} \frac{c_{p v}}{T} d T=c_{p v} \ln \left[\frac{T_{2}}{T_{2 g}}\right] \\
& T_{2}=T_{2 g} \exp \left[\frac{s_{2}-s_{2 g}}{c_{p v}}\right]
\end{aligned}
$$

From Equation (9), we obtain $\mathrm{h}_{2}$ as

$$
h_{2}=h_{2 g}+c_{p v}\left(T_{2}-T_{2 g}\right)=h_{2 g}+c_{p v}\left(t_{2}-t_{2 g}\right)(11)
$$

If the refrigerant was superheated to $t_{1}$, before entering the compressor, $h_{1}$, is obtained as,

$$
h_{1^{\prime}}=h_{1}+c_{p v} \Delta t=h_{1}+c_{p v}\left(t_{1^{\prime}}-t_{1}\right)
$$


$c_{p v}$ is the specific heat of the refrigerant in the vapour state at the evaporator pressure level.

$$
\begin{gathered}
h_{2^{\prime}}=h_{2 g}+c_{p v}\left(T_{2^{\prime}}-T_{2 g}\right) \\
T_{2^{\prime}}=T_{2 g} \exp \left[\frac{s_{2^{\prime}}-s_{2 g}}{c_{p v}}\right] \\
s_{2^{\prime}}=s_{1^{\prime}}=s_{1}+c_{p v} \ln \left[\frac{T_{1^{\prime}}}{T_{1}}\right] \\
T_{1^{\prime}}=T_{1}+t_{s h}
\end{gathered}
$$

$t_{s h}$ is the superheat temperature.

If the refrigerant is subcooled to $t_{3^{\prime}}$ at the condenser exit, $h_{3^{\prime}}$ is obtained as $h_{f @ t 3^{\prime}}$. If the degree of subcooling is given as $\Delta t_{s c}$, then,

$h_{3^{\prime}}=h_{3}-c_{p l} \Delta t_{s c}$

where $c_{p l}$ is the specific heat of the refrigerant in the liquid state and at the given condenser pressure level.

\section{METHODOLOGY}

The state properties are calculated as presented in the theoretical analysis. A code is written in MATLAB to automate the calculations such that the effects of subcooling and superheating on the performance of simple vapour compression refrigeration system could be carried out for any refrigerant. The structure plan (a structure plan is typically written in what is called "pseudocode", that is, combination of statements in English, mathematics and MATLAB, describing in detail how to solve a problem) for the performance analysis is as follows:

- Start.

- State refrigerant properties

- $\operatorname{Get}\left(\mathrm{Q}_{\mathrm{E}}\right) * * \mathrm{Q}_{\mathrm{E}}=$ refrigeration capacity**

- Get $\left(\mathrm{P}_{\mathrm{E}}, \mathrm{P}_{\mathrm{K}}\right)$ : ** $\mathrm{P}_{\mathrm{E}}$ and $\mathrm{P}_{\mathrm{K}}=$ pressure levels at evaporator and condenser respectively**.

- $\quad$ Get $(\mathrm{SNE}, \mathrm{SNK})$ :**SNE and $\mathrm{SNK}=\mathrm{p}_{\mathrm{g}} @ \mathrm{P}_{\mathrm{E}}$ and $\mathrm{P}_{\mathrm{K}}$ respectively**.

- Evaluate $\left(\mathrm{s}_{2}, \mathrm{~s}_{2 \mathrm{~g}}, \mathrm{~T}_{2 \mathrm{~g}}, \mathrm{c}_{\mathrm{pv}}\right): * *$ the entropies at points 2

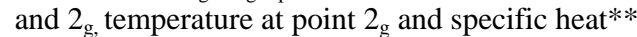

- Evaluate $\left(\mathrm{T}_{2}\right): * *$ the temperature at the compressor exit**

- Evaluate $\left(\mathrm{h}_{2}\right)$ : **the enthalpy at the compressor exit**

- Evaluate $\left(\mathrm{q}_{\mathrm{e}}\right)$ : **the refrigerating effect of the system**

- $\quad$ Evaluate $\left(\mathrm{m}_{\mathrm{f}}\right)$ : **the mass flow rate**

- $\quad$ Evaluate $\left(\mathrm{w}_{\mathrm{c}}\right)$ : ** the compressor work $* *$
- Evaluate (COP): **the coefficient of performance**

- Get $\left(\mathrm{t}_{\mathrm{sh}}\right)$ : **the degree of superheat to be varied after each evaluation, within $0: 1: 20 * *$

- Evaluate $\left(\mathrm{h}_{1}\right)^{\prime}$ : ** the new enthalpy at the compressor inlet**

- Evaluate $\left(\mathrm{T}_{1}\right)$ : **the new temperature at the compressor inlet ${ }^{* *}$

- Evaluate $\left(\mathrm{s}_{2}=\mathrm{s}_{1^{\prime}}\right)$ : **the new entropy at the compressor exit**

- Evaluate $\left(\mathrm{T}_{2^{\prime}}\right)$ : **the new temperature at the compressor exit**

- $\quad$ Evaluate $\left(\mathrm{h}_{2^{\prime}}\right)$ : **the new enthalpy at the compressor exit**

- Evaluate $\left(\mathrm{w}_{\mathrm{c}^{\prime}}, \mathrm{q}_{\mathrm{e}^{\prime}}\right)$ : **the new compressor work and the refrigerating effect under superheat condition**

- $\quad$ Evaluate $\left(\mathrm{m}_{\mathrm{f}}, \mathrm{COPR}\right): * *$ the new mass flow rate and coefficient of performance under superheat condition**

- Display relevant results**

- Get $\left(\mathrm{t}_{\mathrm{sc}}\right): * *$ the degree of subcooloing to be varied after each evaluation within $0: 1: 20 * *$

- $\quad$ Evaluate $\left(\mathrm{h}_{\mathrm{sc}}\right)$ :**the new enthalpy at the subcooled region**

- Evaluate $\left(\mathrm{q}_{\mathrm{esc}}\right)$ : the new refrigerating effect at the subcooled region**

- Evaluate $\left(\mathrm{m}_{\mathrm{fsc}}\right)$ : **the new mass flow rate at the subcooled region**

- Evaluate $\left(\mathrm{COPR}_{\mathrm{sc}}\right)$ : **the new coefficient of performance of the system at the subcooled region**

- Display relevant results

- $\quad$ Plot $\left(\mathrm{t}_{\mathrm{sh}}\right.$ and $\mathrm{t}_{\mathrm{sc}}$, against relevant parameters.

- $\quad$ End

\section{RESULTS AND DISCUSSION}

Results of the effects of superheat on the performance of the two refrigerants are shown in Figures 4 to 7 while those of subcooling are shown in Figures 8 and 9. Both refrigerants show a similar trend in their respective variation with superheat temperatures. The figure show that the refrigerating effect for both refrigerants increase with increasing superheat temperatures. Noted also is the high values obtained in refrigerant R717 which shows that a large amount of heat is involved in the process 


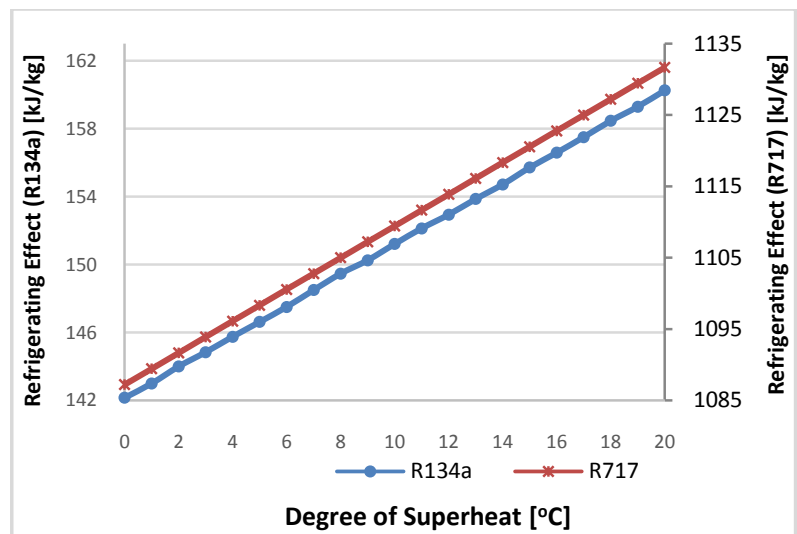

Fig 4: Variation of the refrigerating effect with superheat temperatures

The results obtained in Figure 5 show that the compressor work increases with the superheat temperature in both refrigerants. The compressor work for R717 is higher at all superheat temperatures. This is because of the high heat capacity of R717 compared to R134a. Superheating, as seen in Figure 6, increases the COP of the refrigerant R134a which implies that in order to get a better performance of the refrigerant for refrigeration, the refrigerant should be superheated as much as possible. On the contrary, for the refrigerant $\mathrm{R} 717$ superheating the refrigerant reduces the COP of the system which implies that the refrigerant gives a better performance in the saturated state and thus does not require superheating.

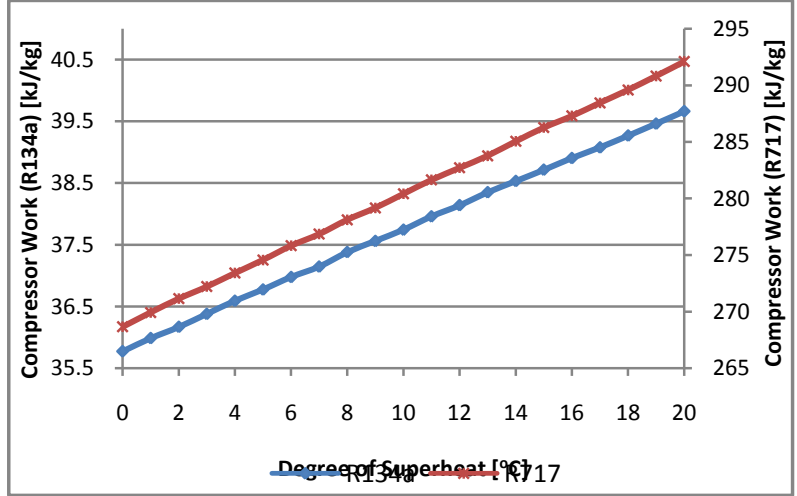

Fig 5: Variation of the compressor work with superheat temperatures

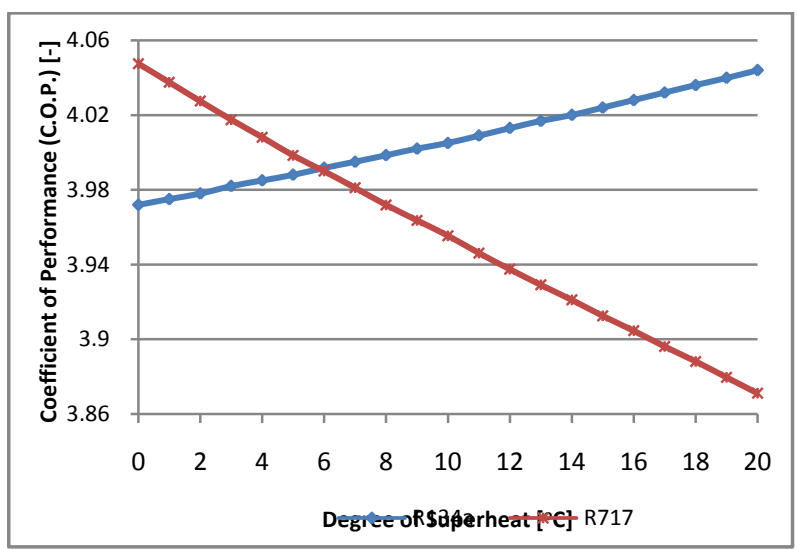

Fig 6: Variation of COP with superheat temperature
The mass flow rates reduce with increasing superheat temperature for both refrigerants as in Figure 7. The smaller mass flow rates associated with R717 is because of its higher heat capacity of the refrigerant.

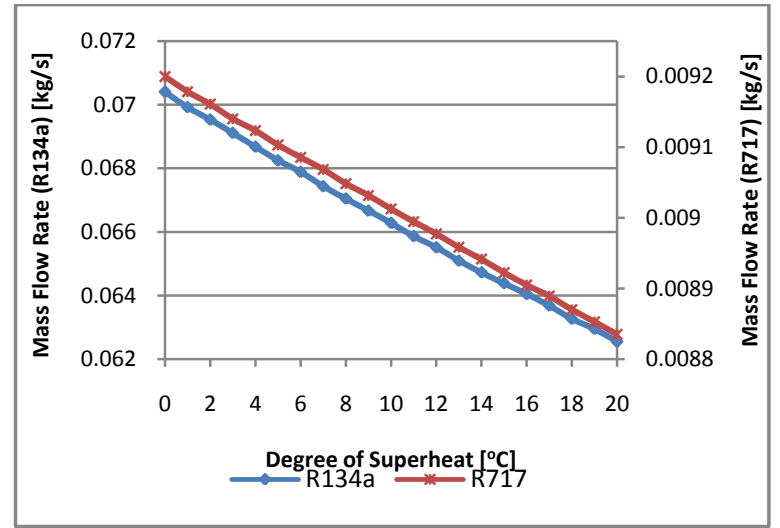

Fig 7: Variation of mass flow rate with superheat temperature

Figure 8 shows that in both R134a and R717, the refrigerating effect increases with the increase in the subcooling temperatures. The high values obtained in refrigerant R717 indicates that subcooling is very effective in using the refrigerant.

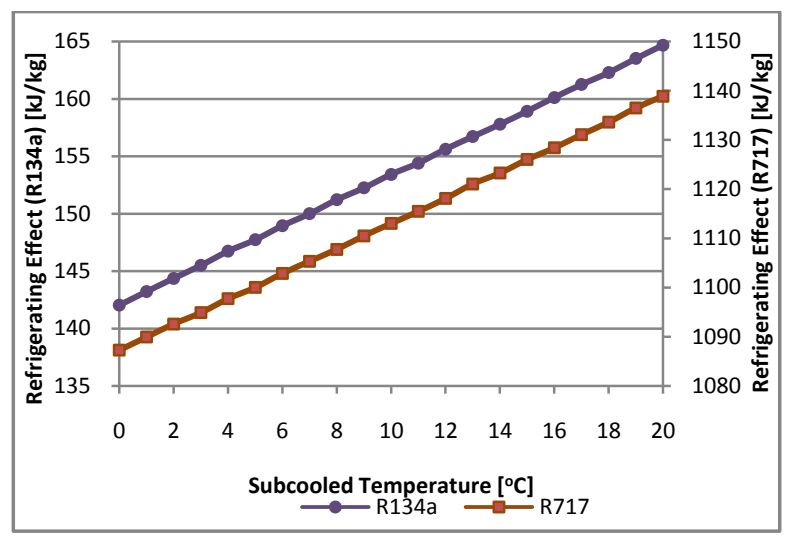

Fig 8: Variation of the refrigerating effect with subcooled temperature

Subcooling both refrigerant R134a and R717 leads to increase in the COP of the respective system and this is shown in Figure 9. Critically looking at Figures 6 and 9 shows that more work is done in subcooling refrigerant R134a than in superheating the refrigerant. Consequently, in as much as subcooling improves the performance of the system, superheating the refrigerant is a better alternative in order to save energy. On the other hand, subcooling refrigerant R717 is a better way to save energy and improve in the performance of the system. 


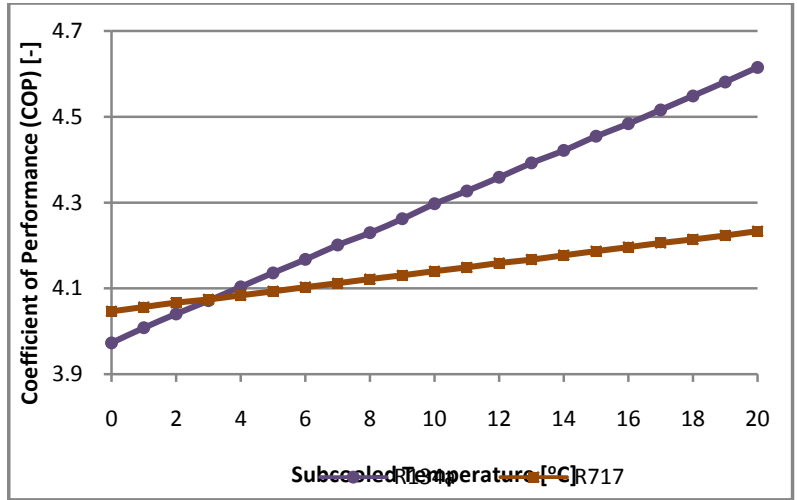

Fig 9: Variation of the COP with subcooled temperature

The mass flow rates of the both refrigerants decreases with increasing subcooling temperature as depicted in Figure 10. The lesser amount of heat used in R717 is evident in the value of the mass flow rates at the subcooled temperatures

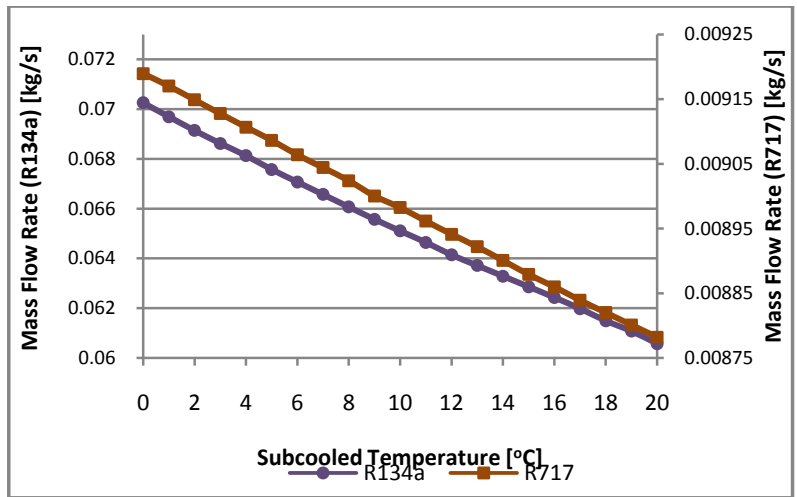

Figure 10: Variation of mass flow rate with subcooled

\section{CONCLUSIONS}

This study has shown that both subcooling and superheating increases the performance of simple vapour compression refrigeration system using R134a as the working fluid, but superheating the refrigerant gives better performance of the system. For simple vapour compression refrigeration system using R717, superheating the refrigerant leads to poor performance of the system as confirmed by other researchers. Subcooling with R717 improves the performance of the system hence this is recommended. A program is developed to carry out the performance of the systems. The program ensures accuracy of results in addition to aiding class room work on the subject area in many ways.

\section{REFERENCES}

[1] J. Vaibhav, S. S. Kachhwaha, and R. S. Mishra, "Comparative Performance Study of Vapour Compression Refrigeration Systems with R22/R134a/R410a/R407c/M20," Int. J. Energy Environ., vol. 12, no. 2, pp. 297-310, 2011.

[2] C. P. Arora, Refrigeration and Air Conditioning, 2nd ed. New Dehli: Tata McGraw-Hill Publishing Company Ltd., 2006.

[3] J. W. Linton, W. K. Snelson, and P. F. Hearty, "Performance Comparison of Refrigerants R-134a and R-12 in a Residential Exhaust Air Heat Pump," ASHRAE Trans., vol. 98, no. 1, pp. 160 - 166, 1989.

[4] J. W. Linton, W. K. Snelson, and P. F. Hearty, "Effect of Condenser Liquid Subcooling on System Performance for Refrigerants CFC-12, FC-134a and HFC-152a," ASHRAE Trans., vol. 95, no. 2, pp. 399 - 404, 1989.

[5] J. Pannock, R. Radermacher, Z. Liu, and K. Yu, "Evaluation of R-134a and R-152a as Working Fluids in a Domestic Refrigerator/Freezer," ASHRAE Trans., vol. 100, no. 1, pp. 1344 - 1350, 1994.

[6] Y. Yi-Yie, L. Hsiang-chao, and L. Tsing-Fa, "Condensation Heat Transfer and Pressure Drop of Refrigerant R-134a in a Plate Heat Exchanger," Int. J. Heat Mass Transf., vol. 42, pp. 993-006, 1999.

[7] C. O. Adegoke, M. A. Akintunde, and O. P. Fapetu, "Experimental Investigation of the Performance of a Design Model for Vapour Compression Refrigeration Systems," West Indian J. Engin., vol. 28, no. 2, pp. 8087, 2004.

[8] C. O. Adegoke, M. A. Akintunde, and O. P. Fapetu, "Comparative Exergetic Analysis of Vapour Compression Refrigeration Systems in the Superheat and Subcooled Regions," A.U.J.T, vol. 10, no. 4, pp. 455 486, 2007.

[9] A. Şencan, R. Selbaş, Ö. Kızılkan, and S. A. Kalogirou, "Thermodynamic Analysis of Subcooling and Superheating Effects of Alternative Refrigerants for Vapour Compression Refrigeration Cycles," Int. J. Energy Res., vol. 30, pp. 323-347, 2006.

[10] A. Arora and S. C. Kaushik, "Theoretical Analysis of a Vapour Compression Refrigeration System with R502, R404A and R507A," Int. J. Refrig., vol. 31, no. 5, pp. 998-1005, 2008.

[11] K. M. Peethambaran and N. K. Asok, "Eco-Friendly Vapour Compression Refrigeration System Simulation Analysis with Double Pipe Evaporator and Condenser." Department of Mechanical Engineering, Government Engineering College, Kerala, Department of Mechanical Engineering, Government Engineering College, Kerala., 2007.

[12] S. M. Zubair, "Performance Evaluation of Vapour Compression System," Int. J. Refrig., vol. 22, pp. 235243, 1999. 